\title{
Ensino de História e consciência histórica de alunos da Educação de Jovens e Adultos: notas investigativas ${ }^{1}$
}

\author{
Teaching History and historical consciousness at Youth and \\ Adult Education: research notes
}

Wilian Junior Bonete ${ }^{2}$

\section{RESUMO}

O presente artigo se propõe a sistematizar alguns resultados de nossa pesquisa de mestrado que procurou investigar o pensamento de alunos jovens e adultos sobre a História e sua função social e se os mesmos atribuíam um sentido prático para a aprendizagem histórica. Em outras palavras, intentou-se analisar o significado do conhecimento histórico para os alunos e em que medida o ensino de História exerce influência na formação de um pensamento crítico e reflexivo a respeito de si mesmos e do mundo contemporâneo. Para tanto, optou-se por uma abordagem consubstanciada na Teoria da História aliada aos pressupostos teórico-metodológicos da Didática da História. As fontes foram interpretadas a partir das respostas dos alunos dadas a um conjunto de questões sobre o conhecimento histórico que envolveu significado, interesse, agrado, confiança, temporalidade, experiências na sala de aula e vida prática.

Palavras-chave: História e Ensino. Didática da História. Consciência Histórica. Aprendizagem Histórica. Educação de Jovens e Adultos.

\section{ABSTRACT}

This article synthesizes some results of our research masters that investigated the thought of youth and adults students about the History and if they confer a practical sense for historical learning. In other words, we investigated the significance of historical knowledge to the students and to what extent the teaching History has influence on the formation of a critical and reflective thinking about themselves and the contemporany world. For this, we chose an approach consubstantiated in the Theory of History allied to the assumptions of Didactics of History. The fonts were interpreted from the students' answers to a set

1 Este trabalho contou integralmente com o financiamento da CAPES e foi realizado sob a orientação da professora Dr. ${ }^{a}$ Regina Célia Alegro.

2 Mestre em História Social pela Universidade Estadual de Londrina (UEL). 
of questions about historical knowledge, which involved meaning, interest, satisfaction, trust, timeliness, experiences in the classroom and practical life.

Keyword: History and Teaching. Didactic of History. Historical consciousness. Historical learning. Youth and Adult.

\section{Introdução}

O presente artigo sistematiza alguns dos resultados que compõem a dissertação de mestrado intitulada "Ensino de História, consciência histórica e a Educação de Jovens e Adultos", defendida junto ao programa de Pós-Graduação em História Social da Universidade Estadual de Londrina (UEL), em 2013. Trabalho que teve por objetivo refletir sobre as relações que os alunos da Educação de Jovens e Adultos (EJA) estabelecem com o conhecimento histórico e se os mesmos atribuem um sentido prático para a aprendizagem histórica. Em outros termos, tratou-se de analisar e identificar o significado do conhecimento histórico para os alunos e em que medida o Ensino de História exerce influência na formação de um pensamento crítico e reflexivo sobre si mesmos e o mundo contemporâneo.

A partir de um instrumento de pesquisa composto por um conjunto de questões envolvendo significado, interesse, gosto, confiança, temporalidade, experiência em sala de aula, conhecimento histórico e vida prática, buscou-se extrair elementos da historicidade e da consciência histórica de um grupo de alunos do Ensino Médio da EJA na cidade de Guarapuava, PR.

Para tanto, foram estabelecidos diálogos com os atuais estudos dedicados a EJA no Brasil, bem como as propostas teórico-metodológicas advindas do campo de estudos da Didática da história alemã em confluência com o conceito de consciência histórica elaborado principalmente pelo autor Jörn Rüsen (2001).

Como pressupostos iniciais, serão abordados nesse texto os elementos que nortearam o percurso investigativo de nossa pesquisa a partir de três perspectivas: a primeira referente à Didática da História e sua confluência com o conceito de consciência histórica, a segunda referente aos trabalhos que privilegiam o ensino de História no âmbito da EJA e por último a análise sobre os significados do conhecimento histórico para os alunos. 


\section{Didática da História e consciência histórica}

A Didática da História - Geschichtsdidaktik - ao longo das últimas décadas tem se estabelecido com um campo híbrido entre a História e a Educação, desenvolvendo objetivos e reflexões teóricas voltadas para diversos temas, dentre eles, a circulação social do conhecimento histórico, a formação de professores, aprendizagem, currículo e as práticas de ensino. (CARDOSO, 2007; 2008). Apesar dessa amplitude temática, seu objetivo vem sendo uníssono: a formação política, crítica e comunicativa dos indivíduos na qual se pretende formular conhecimentos relevantes sobre o passado, procurando transmitir o "saber histórico" de modo que possa ser transformado em habilidades sociais para as novas gerações. (ECKER, 2002).

A Didática da História considera a subjetividade dos alunos, os processos de recepção da História e os interesses desses alunos como tema essencial de suas reflexões didáticas. Entretanto, o seu objeto principal de análise é a consciência histórica (em todas as suas formas e funções) e o seu papel na vida prática humana. (RÜSEN, 2012).

Para Jörn Rüsen, a consciência histórica é um fenômeno do mundo vital e pode ser definida especificamente como: "[...] a suma das operações mentais com as quais os homens interpretam sua experiência da evolução temporal de seu mundo e de si mesmos, de forma tal que possam orientar, intencionalmente, sua vida prática no tempo". (RUSEN, 2001, p.57). A base dessa argumentação assenta-se no pressuposto de que o ser humano deve agir intencionalmente no mundo para viver não o tomando como naturalizado, mas sim construído historicamente. Homens e mulheres devem interpretar mundo em que vivem, de acordo com suas intenções e objetivos de modo a transformar sua realidade, pois, o agir é um procedimento que está na base da manutenção da vida humana.

Na sociedade em constante movimento, o homem é instigado a buscar a concretização de suas metas e objetivos, independente das adversidades. Para isso, projeta-se para além de sua realidade, isto é, para além do que a experiência lhe mostra. Ocorre, segundo Jörn Rüsen, um "superávit intencional" como propulsor de suas ações, resultado da experiência do agir e do sofrer humano no tempo que se processa baseado em dois modos de consciência do tempo: o tempo como experiência e o tempo como intenção. Esse processo também pode ser entendido de forma dialética, pois, ao passo que o homem sofre a ação do tempo e nele age, fica a mercê da perda e atribuição de sentido. Por esse motivo, pode-se dizer que determinadas "carências estruturais" geram simultaneamente novas carências a serem interpretadas.

A consciência histórica não é, pois, um privilégio de alguns indivíduos capazes de pensar à História, mas algo inerente à existência humana, dada junto à intencionalidade da 
vida prática. Em outros termos, consciência histórica é atribuição de sentido ao tempo. (RÜSEN, 2001, p.78).

Nessa mesma direção, Jörn Rüsen destaca que as operações mentais da consciência histórica na memória podem ser designadas como constituição do sentido da experiência do tempo. Esse é um processo da consciência onde a relação dinâmica entre experiência e intenção se realiza no processo da vida humana. É preciso, no entanto, saber fazer a distinção entre esses dois modos de tempo. O termo "sentido" é uma operação mental, cuja finalidade é promover essa síntese.

O tempo é experimentado pelo homem como um obstáculo ao seu agir em todo momento, embora isso não o impeça de querer realizar seus intentos. A consciência histórica, estipuladora do equilíbrio, do sentido, exerce uma função que transcende o passado, pois a capacidade ao recordar é desencadeada pelo impulso das experiências do tempo presente, ou seja, da inserção dos seres humanos na história e sua necessidade de orientação no decurso temporal. Nas palavras de Jörn Rüsen,

Não há outra forma de pensar a consciência histórica, pois ela é o local em que o passado é levado a falar - e o passado só vem a falar quando questionado; e a questão que o faz falar origina-se da carência de orientação da vida prática atual diante das virulentas experiências do tempo. (RÜSEN, 2001, p.63).

É conveniente ressaltar que a consciência histórica não pode ser entendida apenas como passado, tampouco como idêntica a memória ou a lembrança. Jörn Rüsen salienta que não há como negar que toda memória histórica pauta-se pelo passado, porém seria um grande equívoco caracterizar a História e a consciência histórica como uma simples consciência do passado humano. A lembrança é para a constituição da consciência histórica a relação determinante com a experiência do tempo, flui naturalmente no quadro da vida prática, porém, um simples resquício do passado na memória ainda não é fator constitutivo da consciência histórica. (RÜSEN, 2001).

De fato, só se pode falar em consciência histórica quando para interpretar as experiências do tempo, é necessário mobilizar a lembrança no processo dinâmico do movimento de uma narrativa, uma vez que ela rememora o passado sempre com respeito a experiência do tempo presente. Devido a essa relação com o presente é que a consciência histórica articula-se com as expectativas do futuro. (RÜSEN, 2001).

A tensão entre as três dimensões temporais é concebida como uma representação da continuidade, afim de que, por meio dela, os homens possam estipular um quadro interpretativo de suas experiências que os guiem na tomada de ação no presente. Essa 
estrutura única de pensamento (a narrativa) está presente em vários âmbitos da vida humana, seja em um rotineiro ato de fala ou até mesmo nos discursos mais formalizados como aqueles realizados nas universidades, em palestras, conferências, dentre outras.

Outra importante função da consciência histórica refere-se à formação da identidade histórica. O processo da criação e manutenção da identidade, no âmbito da consciência histórica, ocorre pela inserção do sujeito em um tempo social e cultural. A título de exemplo, pode-se pensar no elo da ligação que define um determinado grupo social, seja ele, um símbolo, imagem ou qualquer outra forma de linguagem que torne possível dizer "nós e eles". (KUSNICK, 2008; CERRI, 2011).

Luis Fernando Cerri (2011) comenta que produzir identidade coletiva, e no seu âmbito, uma consciência histórica específica, é algo essencial a qualquer grupo humano que almeja sua continuidade. Entretanto, Jörn Rüsen (2001, p.66) ressalta que a experiência da temporalidade, da contingência, se apresenta como perda iminente da identidade. Cabe aos homens interpretarem essas mudanças mediante as representações da continuidade, instituidora da identidade, pois a narrativa histórica é uma possibilidade indispensável na medida em que ela permite realizar a síntese entre passado, presente e futuro em uma relação de continuidade. Pela narrativa, os homens contam suas vidas, inventam-se e instituem-se como pertencente ao mundo, procurando manter uma personalidade e dar continuidade a sua experiência.

Desse modo é instituída a identidade por meio da memória inserida como determinação de sentido no quadro da vida humana. É útil pontuar que,

A consciência histórica não se caracteriza apenas pela lembrança e memória, mas sempre também pelo esquecimento: somente o jogo do lembrar e do esquecer fornece as referências temporais que o passado tem de assumir, a fim de produzir uma representação de continuidade instituidora de identidade. (RÜSEN, 2001, p.84).

A experiência prática da vida humana no tempo estabelece a necessidade de um quadro interpretativo histórico, a fim de que o homem possa cumprir seus objetivos e agir no tempo. Através da consciência histórica é possível uma apropriação dos elementos que permitem uma orientação no tempo, na sociedade, no mundo contemporâneo.

Em suma, as perspectivas de Jörn Rüsen são privilegiadas, no que tange ao ensino de História, porque caracteriza a consciência histórica como sendo necessariamente um fator humano, que emerge do cotidiano. Isso abre espaço para o entendimento de que os alunos, em geral, são dotados de uma consciência histórica, pois todos são levados a lidar com diversas situações diárias que exigem reflexão e interpretação da realidade e do mundo 
contemporâneo. Nesse sentido, o conhecimento histórico, como elemento da consciência histórica, exerce um papel decisivo na vida dos alunos.

Todavia, é útil ressaltar que a consciência histórica não é um conceito que tem relação apenas com o ensino de História. A consciência histórica cobre todas as formas de pensamento histórico, pois, é através dela que se experiencia o passado e o interpreta como História. Sua análise cobre os estudos históricos, bem como o uso e a função da História na vida pública e privada. (RÜSEN, 2006, p.14).

A noção de consciência histórica, tal como proposta por Jörn Rüsen, não foi aleatoriamente escolhida como elemento central na Didática da História. Pelo contrário, sua orientação disciplinar como objeto para essa área é muito consistente diante da questão de como a História é ensinada e aprendida. Nesse caso, leva em consideração que a consciência histórica é direcionada a organização dos fatores do ensino e aprendizagem, e divide-se em dois aspectos:

(...) em primeiro lugar trata-se de trazer o lado subjetivo que todos os professores e alunos de história têm, a tal ponto que ele não possa apenas ser transportado ou transmitido, mas referem-se sempre, e ao mesmo tempo, a processos determinados de individualização e socialização, nos quais a autocompreensão histórica do sujeito afetado forma sua identidade, por meio de experiências históricas seletivas, normativas e de uma apropriação significativa. Ao mesmo tempo, trata-se de deixar aparecer sobre a folha da vida prática humana, um principio organizador (principalmente do ponto de vista escolar), do ensino e a aprendizagem de história. Isso significa reconhecer sua constituição por meio da presença e orientação objetiva da memória histórica não-organizada, que desempenha um papel importante no equilibrio mental e cultural de um indivíduo. (RÜSEN, 2012, p.71. Grifos nosso).

A Didática da História, por meio da consciência histórica, direciona seu foco para o significado da História na sociedade, ou seja, na produção, circulação e utilização social dos conhecimentos históricos. Segundo Klaus Bergmann (1990, p.30-33), esse campo se subdivide em três aspectos: empírico, reflexivo e normativo:

- O aspecto empírico é a investigação dos conteúdos históricos que são transmitidos, sejam eles nas escolas, nas mídias ou em qualquer outro setor da cultura dos grupos e sociedades. A preocupação maior é, no entanto, com à História e a formação da consciência histórica em um determinado contexto histórico-social. 
- O aspecto reflexivo expõe sistematicamente os processos de ensino e aprendizagem, a formação dos indivíduos, dos grupos e sociedades a partir da e pela História. Nessa direção, investiga e reflete acerca dos conteúdos que poderiam ser transmitidos ou ensinados.

- O aspecto normativo investiga sistematicamente todas as formas da mediação intencional e representação da História, sobretudo do ensino de História. Em outras palavras, propõe os conteúdos a serem ensinados, bem como os métodos, às categorias e possibilidades da estruturação dos conteúdos históricos tanto na escola, como fora dela. Nesse contexto, a Didática da História estabelece uma interface com a Pedagogia, Psicologia e as Ciências Sociais.

Mesmo possuindo fortes vínculos com a História escolar, a Didática da História não visa apenas compreender o contexto escolar isolado (CARDOSO, 2008, p.158), uma vez que os processos de aprendizado ocorrem em diversos e complexos contextos da vida cotidiana. (RÜSEN, 2007, p.91). Esse campo investigativo busca a compreensão do papel da cultura e da consciência histórica na sociedade.

No que se refere à produção acadêmica desenvolvida no âmbito do Ensino de História, e mais especificamente na Didática da História, é possível notar uma ênfase nas temáticas que privilegiam os saberes dos alunos como pontos fundamentais para a construção do conhecimento histórico.

Nesse sentido, convém destacar o projeto Youth and History, realizado durante a década de 1990, em 25 países europeus, incluindo Israel, Palestina e Turquia, com jovens de 15 anos e seus professores, num total de 32 mil entrevistados, sob a coordenação do norueguês Magne Angvik e o alemão Bodo Von Borries. Esse projeto, realizado em forma de survey, teve como objetivo responder questões acerca das características, qualidade e resultados do ensino de História e, particularmente sobre a configuração da consciência histórica de alunos e professores. (CERRI, 2001; 2011; CERRI, MOLAR, 2010). Partiu-se do princípio de que é possível mapear alguns dos principais componentes da consciência histórica através de questões que exponham narrativas reais ou hipotéticas, narrativas abreviadas que exigem interpretações e posicionamentos quanto a temas atuais por parte dos respondentes. ${ }^{3}$ (CERRI, 2011). 
Acerca dos resultados do projeto, Magne Angvik e Bodo Von Borries, segundo Isabel Barca,

[...] reconheceram que as idéias manifestadas pelos jovens de 15 anos em diversos países europeus acerca do passado, presente e futuro são o espelho da mentalidade dos respectivos povos: se os jovens de países mais industrializados se mostram mais críticos face ao passado, os de países com economias mais tradicionais assumem uma postura de maior aceitação e até de entusiasmo face ao estudo da História. (BARCA, 2007, p.117).

A partir dessa constatação chegou-se ao entendimento de que a consciência histórica é culturalmente variável, isto é, mudando o contexto cultural e social, mudam-se as interpretações acerca do passado, percepções do presente e expectativas do futuro. (BARCA, 2007; GERMINARI, 2010). Por outro lado, Luis Fernando Cerri (2011) destaca que a influência do professor sobre a opinião histórica dos alunos é, no mínimo, limitada, assim como é limitada a influência dos currículos sobre o trabalho docente, e permite inferir que:

[...] os elementos narrativos constantes dos currículos oficiais ou da formação que os professores recebem não se reproduzem necessariamente na aprendizagem dos alunos. Assim, é comum encontrarmos opiniões divergentes sobre a história no âmbito oficial, incluindo aí a escola e os alunos que se relacionam com essas esferas [...] (CERRI, 2011, p.44).

A partir disso, entende-se que a formação histórica não depende exclusivamente da escola. Os saberes históricos dos alunos são adquiridos em outras instâncias fora da escola, tais como os veículos de comunicação em massa, a família e o cotidiano, e não devem ser ignorados se a intenção for estabelecer uma relação entre à História ensinada e a consciência histórica dos alunos ${ }^{4}$.

totalmente", passando por "concordo", "indeciso" e "discordo", o que, em estatística é denominado "escala de altitudes" ou "escala de Likert". Os alunos responderam sobre a concepção e importância da História, credibilidade em fontes de conhecimento histórico, descrição e aproveitamento das aulas de História, conhecimentos cronológicos, interesses em períodos ou temas da História, conhecimento e avaliação de mudanças históricas atuais e futuras. Já os professores responderam questões relativas à formação acadêmica, experiência docente, currículos no ensino de História, avaliação da capacidade intelectual dos alunos, significado de religião e política para o cotidiano, seu posicionamento político, trabalhos em sala, conceitos históricos mais importantes, principais problemas no ensino de História no país, fatores da mudança histórica que consideram relevantes e projeção de futuro face as mudanças históricas. Ver Cerri (2011); Cerri e Molar (2010) Germinari (2010).

4 Como exemplo, considere-se a pesquisa de Gláucia Murinelli (2012) que ao analisar, em tempos da Lei Federal 10.639/03, os sentidos e princípios orientadores presentes em narrativas de futuros professores do norte paranaense sobre a história dos afrobrasileiros no contexto pós-abolição, concluiu que a fonte de conhecimento para a elaboração dessas narrativas não estavam pautadas somente na história acadêmica, mas também na história vivida, no cotidiano. A autora 


\section{A produção sobre Ensino de História na EJA e as questões norteadoras de pesquisa}

Ao rever a produção acadêmica desenvolvida no âmbito do Ensino de História e da Didática da História, poucos questionamentos e preocupações foram encontrados acerca do pensamento dos alunos da EJA sobre a História ensinada, a consciência histórica e suas implicações na vida prática.

Nessa perspectiva, destaca-se o trabalho de José Lisboa da Costa (2005) que procurou compreender os significados construídos por alunos adultos - acima de 30 anos - em seus próprios discursos, acerca das relações entre a História ensinada e a História vivida. Para cumprir esse objetivo, o autor fundamentou seus estudos na teoria das representações sociais elaborada por Moscovici, nos conceitos de experiência social, temporalidade histórica, e principalmente, no conceito de consciência histórica proposto por Jörn Rüsen.

Ao final, José Lisboa da Costa apontou que a História vivida, enquanto realidade empírica, não possui o mesmo sentido para todas as pessoas, já que as representações dos alunos apresentaram perspectivas distintas entre si. Segundo o autor, isso se deve ao fato de que cada aluno, ao vivenciar a realidade social, a partir de suas particularidades, as interioriza de acordo com a compreensão que tem de si mesmo, do real e do imaginário social. No entanto, essas diferentes visões de mundo, ou diferentes consciências históricas, são interligadas por um elemento em comum: a História socialmente vivida. (COSTA, 2005, p.126).

Claudia Hickenbicki (2009), por sua vez, trabalhou em uma perspectiva semelhante, porém analisou diários de campo, depoimentos e questionários não apenas de alunos, mas de professores, coordenadores pedagógicos e funcionários da EJA da Rede Municipal de Florianópolis, SC. Pautada nos conceitos de consciência histórica e formação histórica elaborados por Rüsen, a autora buscou investigar o significado da História para os sujeitos envolvidos na pesquisa, as relações por eles estabelecidas, através da lembrança escolar, com o conhecimento histórico e as suas ideias em termos de compreensão disciplinar.

Segundo a autora, os resultados apontaram que, para os alunos, a escola é vista com o lugar privilegiado para se aprender História. Porém, nas entrevistas eles estabeleceram profundas relações entre o conhecimento histórico escolar e aquele veiculado pela televisão,

\footnotetext{
destaca que a argumentação dos graduandos se aproxima muito das fundamentações do sociólogo Florestan Fernandes (mesmo de maneira inconsciente, pois foi mencionado apenas uma vez entre todos os participantes que indicaram as suas referências), no entanto, os conhecimentos adquiridos fora do âmbito universitário que condicionam os afrobrasileiros a "crueldade e sofrimento" permaneceram ao longo de suas formações.
} 
salientando a influência dos meios de comunicação em massa. Em termos de lembrança sobre a História escolar, os alunos apontaram apenas questões ligadas à didática dos professores, sendo que praticamente não se verificou a presença de conteúdos históricos, ou História substantiva. Não houve questionamentos acerca da validade do estudo da História, mas por outro lado, houve a existência de interesse dos alunos "pelas histórias de vida, porém não as suas próprias histórias, mas, aquela contida nas vidas e experiências de outras pessoas, em outros tempos, que poderiam influenciar o presente". (HICKENBICKI, 2009, p.138).

Josiane Pádua (2008) buscou observar o processo de construção do conhecimento histórico por alunos da EJA através das práticas de escrita e leitura. Pautada em referencias como Roger Chartier, Robert Darnton e Peter Burke, e na metodologia da história oral, a autora procurou perceber até que ponto as práticas de leitura favoreciam a formação de conceitos e saberes históricos que possibilitam, além da interpretação dos fatos, uma leitura de mundo.

Os resultados finais da pesquisa indicaram que as relações estabelecidas pelos alunos entre a leitura, a escrita e o conhecimento histórico diferem-se daquelas que estão nos livros e daquela que se aprende na escola. Elas são construídas principalmente a partir das vivências e experiências sociais, apresentadas em forma de narrativas de acontecimentos pessoais rememorados. (PÁDUA, 2008, p.97-98).

Embora o trabalho de Josiane Pádua (2008) tenha partido de outra perspectiva analítica, entende-se que os sujeitos, ao manifestarem suas ideias, conceitos, suas práticas de leitura e escrita, estão necessariamente mobilizando o pensamento histórico, e consequentemente a consciência histórica. Nesse processo de construção do conhecimento, a consciência histórica mostra-se relacionada intimamente com a experiência social, a experiência de vida e a História vivida.

A partir do esboço apresentado do projeto Youth and Historye também dos trabalhos de José Lisboa da Costa (2005), Cláudia Hickenbicki (2009) e Josiane Pádua (2008), infere-se que, o indagar sobre as ideias, os saberes e o aprendizado dos alunos, significa refletir sobre a consciência histórica. Jörn Rüsen corrobora para essa apreensão afirmando que:

O aprendizado é uma das dimensões e manifestações da consciência histórica. É o processo fundamental de socialização e individualização humana e forma o núcleo de todas estas operações. A questão básica é como o passado é experienciado e interpretado de modo a compreender o presente e antecipar o futuro. Teoricamente, a didática da história tem de conceituar a consciência histórica como uma estrutura e processo de aprendizado. Aqui é necessário reformular a idéias sobre a consciência histórica como sendo um fator básico na formação da identidade humana relacionando estes conceitos com o processo 
educacional que também é básico para o desenvolvimento humano. (RÜSEN, 2006, p.16).

Os pressupostos teórico-metodológicos advindos da Didática da História e sua relação com o conceito de consciência histórica em Jörn Rüsen possibilitaram a formulação da questão central discutida ao longo da pesquisa: $O$ que pensam os alunos da EJA a respeito da História e sua Função Social?

A partir dessa questão procurou-se então analisar e compreender as relações que um grupo os alunos do Ensino Médio da EJA estabelecem com o conhecimento histórico e como se dá sua aplicação, como consciência histórica, na vida prática. Para responder a essa problemática, outras questões específicas foram elaboradas, como: qual é o significado do conhecimento histórico para os alunos da EJA? Quais são suas ideias e interesses sobre a História? O ensino de História tem importância na vida dos alunos no que se refere à construção de um pensamento crítico e reflexivo acerca de si mesmos e do mundo contemporâneo?

\section{Consciência histórica dos alunos jovens e adultos: reflexões e análises}

A pesquisa ocorreu junto a um grupo de 66 alunos jovens e adultos ${ }^{5}$ de três turmas do Ensino Médio de uma escola da Rede Estadual de Ensino que oferta exclusivamente a modalidade EJA, na cidade de Guarapuava, $\mathrm{PR}^{6}$

Para cumprir os objetivos propostos foi elaborado um instrumento de pesquisa - fontes - composto por duas partes. Na primeira parte (Dados Gerais) foram solicitadas informações destinadas à criação de um perfil básico dos alunos que possibilitassem uma aproximação com suas trajetórias, experiências de vidas e expectativas ao adentrarem a escola. $\mathrm{Na}$ segunda parte (Informações Específicas) foram elencadas 15 (quinze) questões divididas da seguinte forma: 10 (dez) questões históricas sobre significado, importância, gosto, interesse, confiança, experiência em sala de aula e temporalidade, de acordo com aquelas que foram propostas nos projetos Youth and History e Jovens Diante da História ${ }^{7}$, porém readaptadas

\footnotetext{
5 Esse número refere-se ao total de alunos que estiveram presentes nas aulas em que o instrumento de pesquisa foi aplicado.

60 município de Guarapuava está situado no Terceiro Planalto Paranaense, logo acima da Serra da Esperança, a 1.120 metros do nível do mar, com área total de $31.177,598 \mathrm{Km}^{2}$, e população estimada de 169.252 habitantes, segundo os dados do Instituto Paranaense de Desenvolvimento Econômico e Social. (IPARDES, 2012).

7 Esse projeto, inspirado no projeto Youth and History, é desenvolvido sob a coordenação do professor Luis Fernando Cerri (UEPG) em três países da América Latina: Brasil, Argentina e Uruguai. Para mais, ver Cerri e Molar (2010); Cerri (2011a; 2011b).
} 
aos alunos da EJA; 4 (quatro) questões, que exigiram respostas discursivas, acerca do conhecimento histórico e sua relação com a vida prática; e por último, uma questão de múltipla escolha, baseada em uma situação hipotética, inspirada em Rüsen (2010) cujas alternativas remetem às diferentes dimensões da consciência histórica.

Os dados obtidos através das questões fechadas foram analisados mediante o uso da Escala Likert, habitualmente utilizada em questionários e pesquisas de opinião na qual os participantes especificam seu nível de concordância. Em outras palavras, "esta escala consiste em uma maneira de se verificar como as pessoas vêem um grupo, uma questão social ou uma experiência de vida". (JOHNSON, 1997; CERRI, MOLAR, 2010). Em nossa pesquisa foram estabelecidos três níveis de concordância (discordo, concordo e concordo totalmente) cujas respostas foram traduzidas numericamente, por meio de tratamento estatístico, e geraram médias (porcentagens) que possibilitaram a visualização de um quadro geral representativo para cada questão.

Para a análise das questões discursivas fez-se uso da metodologia da "Análise de Conteúdo" proposta por Lawrence Bardin (1977) e Roque Moraes (2003). Para esses autores, a análise de conteúdo procura, através da organização, categorização e interpretação, revelar às minúcias e os sentidos manifestados, e/ou ocultos, nos diversos tipos de discursos, tanto em fontes existentes como aquelas produzidas.

Antes de avançar nas reflexões sobre o conhecimento histórico, é oportuno destacar que $42 \%$ dos alunos participantes da pesquisa situam-se na faixa etária entre 18 a 25 anos de idade, seguidos daqueles entre 26 a 35 anos (24\%). O público da EJA, na escola selecionada, é formado, em sua maioria, por alunos adultos, conforme mostra a tabela abaixo:

Dados relativos à idade

\begin{tabular}{|c|c|c|}
\hline Idade & $\mathrm{N}^{0}$ alunos & Porcentagem \\
\hline $18-25$ & 28 & $42 \%$ \\
\hline $26-35$ & 16 & $24 \%$ \\
\hline $36-45$ & 13 & $20 \%$ \\
\hline $46-60$ & 6 & $9 \%$ \\
\hline Não responderam & 3 & $5 \%$ \\
\hline Total & 66 & $100 \%$ \\
\hline
\end{tabular}

Os dados da pesquisa demonstraram que vários alunos estavam afastados dos estudos e retornaram motivados principalmente pela "família", cujo intuito maior, além de "aprender", seria ingressar em um curso de nível superior. Nesse sentido, a última questão, proposta na primeira parte do Instrumento de Coleta de Informações (ICI) teve por objetivo 
verificar, nas palavras dos próprios alunos, quais eram suas expectativas, ao chegarem à escola. Para tanto, questionou-se:

Quando você vai à escola, o que espera que aconteça?

No total, obteve-se 63 respostas que apontaram para a seguinte categorização:

Categorização das respostas

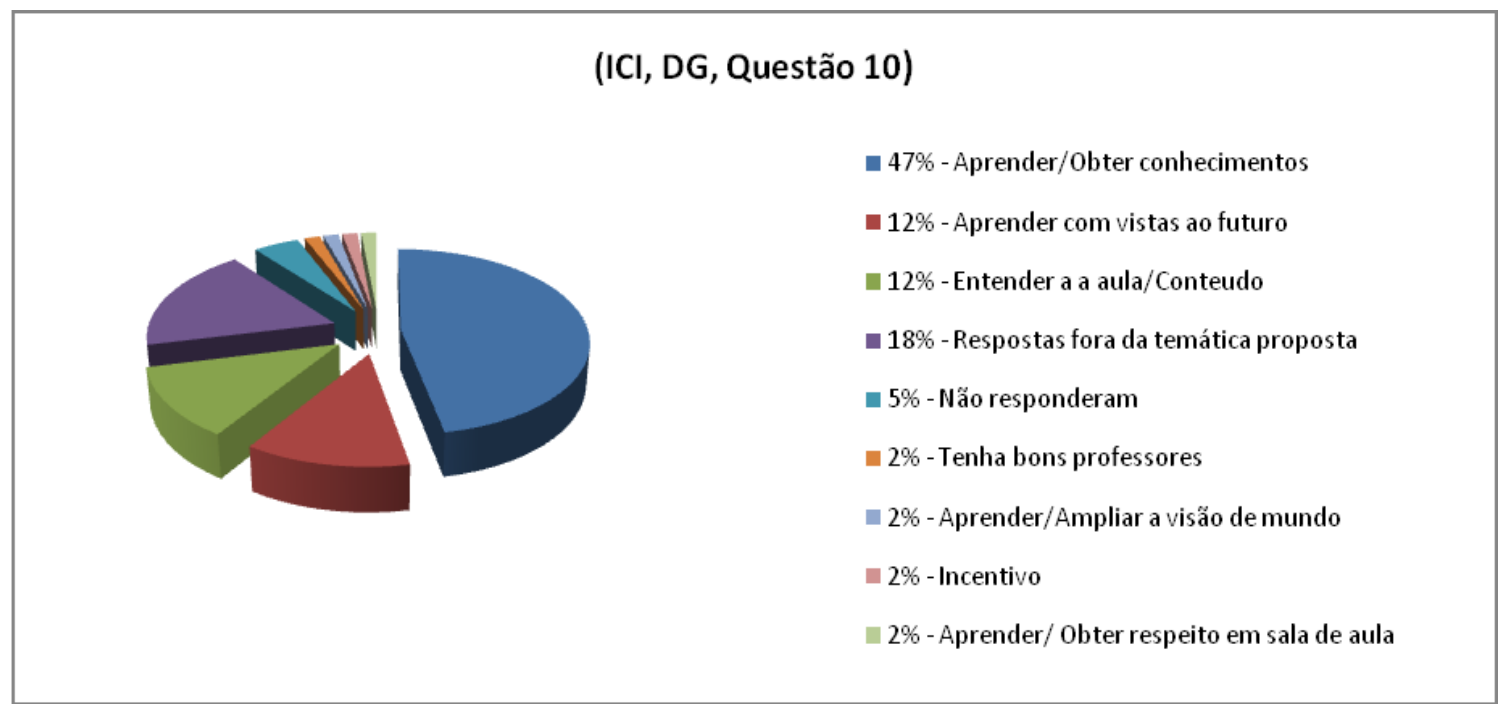

Como pode ser pode ser observado, várias categorias foram identificadas. No entanto, o índice mais expressivo refere-se àquele grupo de alunos que adentra à sala de aula com a expectativa de aprender ou obter conhecimentos (47\%). Outro dois grupos apontaram que, além do aprendizado, a expectativa é entender os conteúdos propostos (12\%) e que os mesmos sejam úteis de alguma forma para o futuro (12\%). No quadro abaixo, foram selecionados alguns fragmentos: 
Quadro de Argumentações ${ }^{8}$

Aprender/Obter conhecimentos
GM15 L1-4: espero pode aprender (...) tornar uma pessoa culta e com bons estudos
GM12 L1-2: venho a escola para adquirir conhecimentos, experiências novas.
GM6 L1: espero aprender muitas coisas interessantes
GM 17 L1: espero obter sempre mais conhecimentos.
Aprender com vistas ao futuro
GM10 L1-2: conhecer coisas novas, aprender e ter um futuro melhor.
MM13 L1: espero aprender coisas que eu irei usar no futuro.
MM18 L1-3: que eu possa me dedicar e aprender e ter conhecimento para buscar meus objetivos.
MM20 L1-2: espero ter mais conhecimento para ter novas oportunidades de qualificação.
PM13 1 1-3: Espero aprender, a compreender para melhor me espressar e conseguir um futuro
promissor.
Entender a aula/Conteúdo
GM18 L1-2: espero aprender o conteudo da matéria que estou fazendo.
MM3 L.1-2: que eu consiga entender e aprender os conteúdos.

Dentre essas respostas e categorizações, um fragmento chamou a atenção pela intensidade e expectativa do aluno com relação aos seus estudos:

Quando venho a escola, espero aprender coisas novas, novas maneiras de ver a vida o cotidiano, ter uma mente mais aberta, imaginário principalmente centrado. (PM10 L1-3).

Para esse aluno, o conhecimento pode proporcionar uma nova visão sobre o mundo e sobre a vida em vários aspectos. No geral, os alunos investigados possuem grandes expectativas com relação à escola. Acreditam que o conhecimento adquirido através das disciplinas escolares pode ser uma porta para enfrentar o mundo, alçar novos objetivos e proporcionar “(...) novas oportunidades”. (MM20, L2). De posse desse fragmento do perfil e expectativa dos alunos, é possível estabelecer algumas reflexões e análises da segunda parte do Instrumento de Coletas de Informações (ICI) intitulado Informações Específicas (IE).

8 PM, GM e MM referem-se às nomenclaturas dadas aos alunos participantes da pesquisa no intuito de preservar suas identidades. Convém destacar que foi privilegiada a escrita original dos alunos, o que por sua vez justifica eventuais equívocos gramaticais. 
Ao longo deste estudo, tem sido sustentado o argumento de que a consciência histórica é algo universalmente humano que emerge do cotidiano como forma de orientação e equilíbrio para a vida prática (RÜSEN, 2001). A História, enquanto conteúdo da consciência histórica representa o nexo significativo entre as três dimensões temporais: o passado e a forma como ele é interpretado, o presente e como ele é vivido, o futuro e como ele é configurado. (RÜSEN, 2010, p.57; PAIS, 1999).

Entretanto, a História não possui um sentido independente daquele que as pessoas lhe atribuem. Assim, uma investigação acerca da consciência histórica consiste no empenho de identificar e analisar como as pessoas veem e convivem com o passado, uma vez que o utilizam como conhecimento. Segundo José Machado Pais (1999, p.1), o que está presente na consciência histórica são múltiplas representações e, no final, são elas que conferem sentido à História.

Assim, a primeira parte da análise objetivou refletir a respeito dos significados, representações, interesses e a confiança dos alunos sobre a História e o ensino de História. Pelas respostas verificou-se grande rejeição das imagens negativas da História que a mostram como sendo apenas uma "matéria escolar" ou algo que já "morreu e não tem sentido para a vida". Ao contrário disso, os alunos indicaram que a História possibilita a compreensão da sociedade, da realidade, do presente e da vida pessoal como parte das mudanças que ocorrem no mundo contemporâneo.

No que tange ao agrado, os alunos indicaram para uma aprendizagem mais prazerosa, principalmente os filmes, documentários, museus e lugares históricos. Além disso, também indicaram gostar mais da fala de outros adultos (avós, tios, etc.) do que da fala dos professores e os tradicionais livros escolares. Por outro lado, no que se refere à confiança nessas formas, a ordem se inverteu, pois grande parte dos alunos apontou para os professores, os museus, lugares históricos e os livros escolares como fontes mais confiáveis para a aprendizagem histórica. Por esses resultados observou-se que a forma mais agradável de aprender História não corresponde necessariamente ao mesmo nível de confiança.

No que se refere aos gêneros (ou assuntos) que despertam maiores interesses, a "História da Família" obteve o maior índice de respostas, o que denota um importante indicativo da consciência identitária. Outros gêneros como a "formação e cultura de outros países", "aventureiros e descobridores", "o desenvolvimento da democracia", "guerras e ditaduras", assuntos específicos como "história dos carros, da igreja, do desenvolvimento do comércio, da agricultura e da economia", revelaram grande interesse por parte dos alunos.

Nessa perspectiva, perguntou-se também sobre quais espaços os alunos mais possuíam interesses de estudar. As respostas incidiram sobre a História do Brasil e do Paraná, revelando grande valorização da localidade em que os alunos estão inseridos em relação à História de outros lugares do mundo. 
No segundo momento da análise, pautado nos pressupostos da Didática da História que possui no seu rol de interesses investigativos as práticas de ensino, procurou-se identificar, pelas respostas dos alunos, o que normalmente acontecia nas aulas de História e no que elas mais se concentravam. Esse questionamento foi elaborado, partindo do princípio de que o modo como a História é ensinada exerce influência direta na formação do pensamento histórico e, consequentemente, na consciência histórica dos alunos, embora esse não seja o único fator.

Conforme os alunos sinalizaram, "frequentemente" as aulas de História em que participavam desenvolviam-se com base na exposição, explicação e discussão dos professores sobre o passado, com a utilização de livros didáticos, mas também na pesquisa em fontes como imagens, figuras, mapas e outros documentos. Já os trabalhos com vídeos, filmes, músicas, documentários ou até mesmo visitações em museus e lugares históricos, foram marcados como ocorrências eventuais. Quando questionados acerca do que mais se concentravam suas aulas, os alunos sinalizaram majoritariamente "conhecer os principais fatos da História" e compreender o comportamento das pessoas, no passado, levando em consideração o momento em que viviam. É importante destacar que os alunos também indicaram o uso da História como um fator para o entendimento da sociedade, das tendências de mudanças e também como uma forma de conhecer as tradições, os valores e a missão da nação.

Por esses dados, é possível perceber que os alunos entravam constantemente em contato com fatos históricos, com exposições e explicações sobre o passado, porém, demonstraram entender que a História é uma importante chave para a compreensão da contemporaneidade.

Considerando que o tempo é um fator primordial na constituição da vida humana e da consciência histórica, buscou-se averiguar como os alunos da EJA lidavam com a questão da experiência de vida e a temporalidade. Para tanto, os alunos foram convidados a projetar o futuro do Brasil e o de suas vidas para nos próximos 20 anos. O objetivo era verificar em que medida as projeções seriam construídas a partir do presente e quais seriam as reflexões mobilizadas.

Os alunos projetaram um futuro bastante pessimista para o Brasil. Indicaram que "muito provavelmente" as terras brasileiras serão um lugar "poluído", marcado principalmente por "conflitos políticos" e "conflitos entre ricos e pobres". Por essas respostas, é possível inferir que houve uma análise e reflexão, por parte dos alunos, sobre a realidade atual, em face das mudanças que estão ocorrendo no cenário político e econômico a nível nacional, o que, por sua vez, é revelador das desigualdades sociais.

Por esses motivos acima arrolados, os alunos são banhados por uma onda de incertezas quanto ao futuro do Brasil, a qual os levou a crer que o país não será "próspero e rico, 
"democrático", tampouco será um lugar "pacífico" para se viver, visto que "sofrerá com a "exploração de outros países". No que diz respeito às representações de suas próprias vidas nos próximos 20 anos, projetaram um futuro com boas expectativas em contraposição às representações feitas para o Brasil. Com exceção das respostas que afirmaram incertezas quanto a se ter liberdade política e individual e rendimentos elevados, a certeza mais consensual que se desenhou referiu-se à família e aos amigos. Muitos também projetaram um trabalho prazeroso e tempo livre para o exercício de atividades de lazer.

No entanto, convém destacar que, independentemente dos tipos de projeções que os alunos possam fazer sobre o Brasil e suas vidas, o tempo um fator primordial para a constituição da consciência histórica da experiência humana. Apesar das projeções de um Brasil pessimista há de se considerar que com os alunos, com suas experiências, são agentes de mudanças em meio às transformações da sociedade.

$\mathrm{Na}$ sequência da análise objetivou-se verificar o pensamento dos alunos sobre o processo de ensino-aprendizagem da História e suas relações com a vida prática. Para tanto, questionou-se acerca do que os alunos mais valorizavam no estudo da História: conhecer o passado? Compreender o presente? Buscar orientação para o futuro? Ou seria a ligação entre as três dimensões temporais? Do total dos alunos investigados, 65\% afirmaram "as três dimensões temporais" e a categorização majoritária das respostas descritivas apontou para "Orientação para a Vida Prática". Os participantes mais uma vez afirmaram que a História possui um sentido prático que auxilia na compreensão do passado e na articulação das três dimensões temporais.

Esse resultado remeteu a seguinte questão: até que ponto o conhecimento histórico se relaciona com a vida prática? Ou melhor, a História aprendida na escola é realmente importante para a formação pessoal? As narrativas dos alunos mantiveram a mesma lógica da questão anterior e foram identificadas as seguintes categorizações: "Entendimento da sociedade/atualidade", "Entendimento do passado em comparação com o presente" e "Ampliação da visão crítica de mundo". Averiguou-se que, para esses alunos, a mobilização do pensamento histórico e da consciência histórica é uma forma de entender o mundo em sua historicidade e também de agir intencionalmente sobre ele, com vistas a melhorá-lo.

De modo articulado as essas questões procurou-se instigar os alunos a descreverem algum fato ou acontecimento histórico que, porventura, tenha marcado suas vidas. Essa reflexão mostra-se relevante, pois a lembrança, a memória e o esquecimento são elementos importantes para a constituição da consciência histórica. (RÜSEN, 2001; CERRI, 2011).

Durante o processo da análise e categorização, a expectativa inicial era de que os alunos relatassem fatos ou acontecimentos ligados à história familiar, em virtude da valorização desse gênero nas questões anteriores. Todavia, indicaram acontecimentos normalmente trabalhados nas aulas de História, mas, mesmo assim, apontaram o significado para suas 
vidas. Dentre os fatos relatados, os mais citados foram: "11 de Setembro de 2001", "Escravidão e Abolição", "Nazismo" e "Guerra do Paraguai". Esses fatos históricos foram relacionados partindo de uma ordem individual, visto que alguns alunos eram afrodescendentes e descendentes de paraguaios e também devido ao grau de "desrespeito e atrocidade cometido entre os seres humanos", o que, por sua vez, conduziu uma reflexão acerca da própria vida.

Diante de todos os argumentos dos alunos relacionados, tendo em vista que a maioria salientou a importância da História e suas implicações na vida prática, procurou-se analisar o pensamento dos alunos acerca do contexto da produção histórica. Para tanto, questionou-se: do que é feita a História? Quais são os elementos que compõe o conhecimento histórico? Como é produzida a História dos livros didáticos?

Verificou-se, assim, que, para $45 \%$ dos alunos investigados, a História é feita de fatos e acontecimentos, resultado que entrou em contradição com as respostas da questão 1 , na qual a maioria dos alunos salientou a importância da História para o entendimento da realidade e da sociedade. Por outro lado, essas respostas convergem com as indicações das aulas de História que se baseavam na compreensão dos "principais fatos da História" e na "explicação e discussão sobre o passado". Convém destacar que outro grupo de alunos (17\%) indicou que a História é feita a partir das "Ações humanas no tempo". Esses alunos enxergaram-se como sujeitos da História e avançaram na noção de História e sua Função Social.

Embora algumas respostas dadas à questão "Do que é feita a História" não foram congruentes com as outras afirmativas, é necessário considerar que nem todos os alunos possuem interpretações idênticas. A leitura do mundo, das situações ou até mesmo de uma simples questão, depende de uma série de fatores, visto que a consciência histórica é múltipla e engloba experiências, representações, identidades, valores morais, memória, esquecimento, sentido e vida prática.

Nesse contexto, os alunos puderam ainda responder como pensavam que era produzido a História presente dos livros didáticos. Do total dos alunos, $45 \%$ afirmaram, com ênfase, que a História e o livro didático são frutos de "muitas pesquisas e estudos", sobretudo, em análises de documentos, fontes e outros tipos de documentos ou vestígios.

O pensamento dos alunos não está equivocado, pois certamente o trabalho de pesquisa é um fator importante, porém outros fatores estão envolvidos, como o ideológico, político, exigências mercadológicas e também educacionais. (FONSECA, 2003). Apenas um aluno relatou que ouviu dizer que "os conteúdos são impostos pelo Estado". Ao final, constatou-se que os alunos desconhecem totalmente o processo que envolve a produção do livro didático, muito embora confiem nesse material. 
Por último, buscou-se perceber de forma mais direta a consciência histórica dos alunos da EJA e, assim, visualizar o modo de como lidariam com situações que exigem tomadas de decisões ou atitudes. Para tanto, propôs-se uma situação hipotética (fictícia) ${ }^{9}$ com quatro desfechos possíveis, cada uma representando uma dimensão da consciência histórica: tradicional, exemplar, crítica e genética. Ao final, foi constatado que os alunos, nessa situação, mobilizaram principalmente a dimensão crítica $(59,1 \%)$ e a dimensão genética (27,3\%) da consciência histórica.

A dimensão crítica da consciência histórica tem por característica anular os padrões dominantes na cultura histórica vigente e procurar abrir espaço para novas interpretações na vida prática. Aqueles que adotam essa postura crítica constroem suas narrativas com base em aspectos contrastantes da memória histórica que desestruturam as narrativas estratificadas e canonizadas na mentalidade das diversas instituições. Por essa dimensão, as pessoas defendem sua identidade, no tempo e no espaço, a partir da negação dos padrões vigentes. A dimensão genética da consciência histórica se assemelha em determinados aspectos com a dimensão crítica. Ela nega as formas dominantes na cultura histórica, porém localiza o sujeito na dinâmica da duração e procura compreender as ações humanas a partir do contexto em que elas se desenvolvem, ou seja, sua historicidade. Isso, por sua vez, possibilita indagar e refletir sobre as mudanças e permanências, sobre a evolução ou involução do processo histórico.

Ao examinar o resultado geral das questões, foi possível observar, de acordo com o pensamento histórico dos alunos, que eles se aproximam muito de uma consciência crítica e genética a respeito da História e sua função social. Crítica porque conceberam a História e o conhecimento histórico como elementos fundamentais para o entendimento e interpretação da sociedade, da realidade e da atualidade, a partir de suas experiências individuais e sociais. Genética porque puderam se perceber como sujeitos históricos, apropriaram-se do conhecimento histórico e a relacionaram com suas vidas, partindo do princípio de que são as ações que explicam as mudanças e as permanências no tempo, na História.

Essas duas dimensões da consciência histórica também se mostraram presentes quando os alunos foram questionados a respeito de suas relações e experiências com a temporalidade. Foi possível verificar que as representações do futuro do Brasil, embora pessimistas, não se desvincularam da realidade política, econômica e social vivenciada na atualidade. Quanto às representações de suas vidas no futuro, os alunos não se distanciaram radicalmente das afirmações anteriores, uma vez que projetaram a falta de liberdade individual e política, além de projetarem também baixas expectativas no que se refere a rendimentos elevados, quadro justificado pelas suas formas de inserções no mercado de trabalho.

9 Esta história fictícia foi inspirada tanto no conto proposto por Jorn Rüsen (2010), quanto na história criada por Caroline Pacievitch (2006). Conferir o anexo 1. 
A partir dessas reflexões é necessário mais uma vez ressaltar a potencialidade do ensino de História para a formação do pensamento histórico dos alunos, isto é, a capacidade de identificar e explicar as permanências e rupturas entre o passado, o presente e futuro. A essa perspectiva acrescente-se a experiência individual, que, no caso dos alunos da EJA, já possuem uma trajetória de vida, uma bagagem cultural mais ampla, além de ideias e opiniões arraigadas sobre si e o mundo que os cerca.

\section{Consciência histórica dos alunos da EJA: entre constatações e aproximações}

Ao pontuar a análise final das respostas dadas ao Instrumento de Coleta de Informação (ICI), seção Informações Específicas (IE), verificou-se a existência de um fio condutor das ideias dos alunos sobre a História, que aponta para a existência das dimensões predominantes da consciência histórica verificadas na questão hipotética de número 15.

Desde a primeira questão observou-se que os alunos da EJA salientaram a importância do ensino de História valorizando os aspectos críticos e reflexivos do conhecimento, bem como as suas contribuições para o entendimento da atualidade, da sociedade e da realidade. Essas ideias ganharam clareza nas respostas discursivas quando os alunos mantiveram os mesmos princípios e lógicas que vinham se delineando ao longo do inquérito. Mediante ao resultado geral, constatou-se que os jovens e adultos se aproximam, principalmente de um pensamento "crítico", seguido do "genético", sobre a História e sua função social.

Na dimensão crítica destaca-se a habilidade dos alunos em conceberem o conhecimento histórico como um dos elementos fundamentais para a interpretação da sociedade e da realidade a partir das experiências sociais, construindo reflexões que resgatam características do passado, mostrando as diferenças e semelhanças com relação ao tempo presente. $\mathrm{O}$ quadro abaixo apresenta algumas destas expressões: 
Expressões da dimensão crítica da consciência histórica

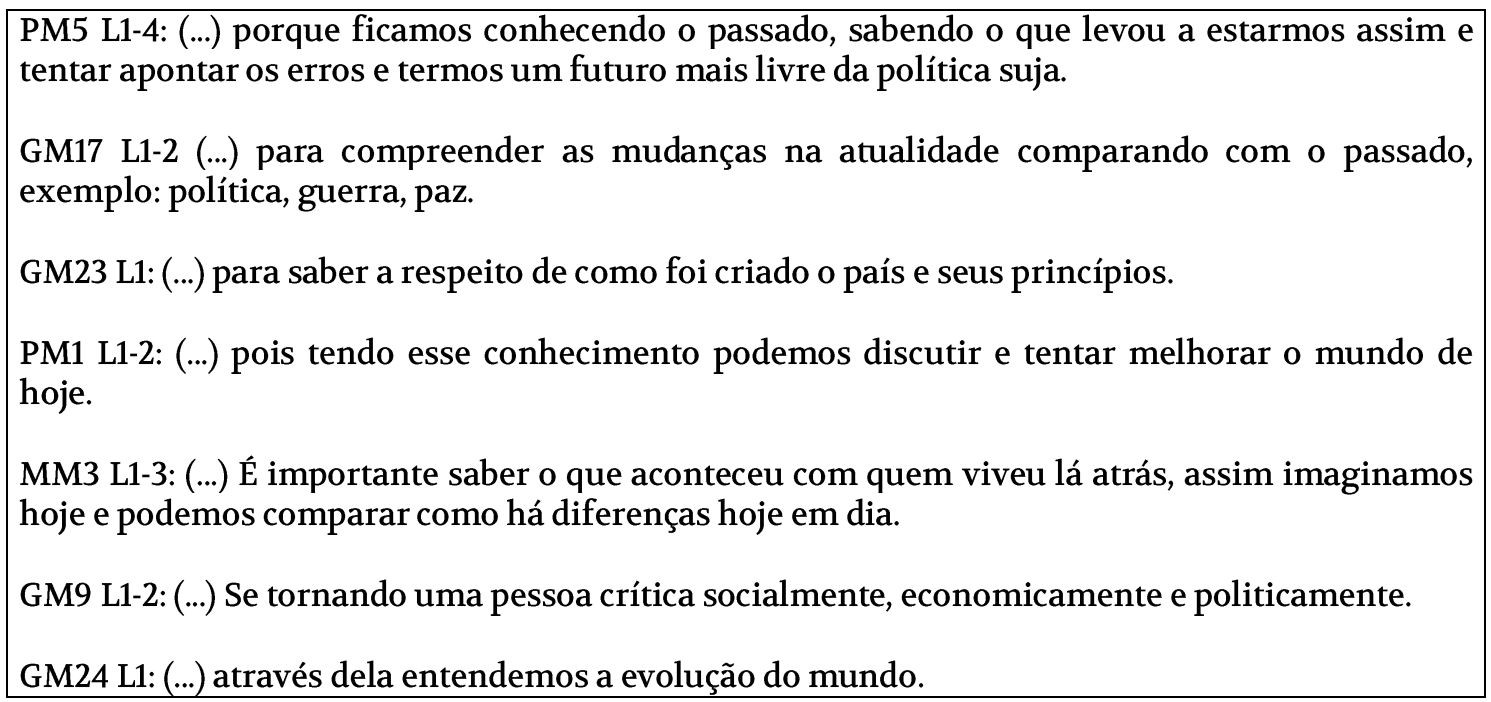

Atente-se que, na dimensão crítica da consciência histórica dos alunos, as representações do passado são valorizadas, tendo em vista as argumentações sobre a necessidade de se olhar para o passado, porém não como lições a serem assimiladas, mas, como antagonismos a partir do tempo presente, a serem superados. José Lisboa da Costa (2005, p.147) afirma que, diferente da dimensão "tradicional" e "exemplar", concebida como modelos e respostas ao presente, a dimensão "crítica" procura problematizar, liberar a subjetividade, interpretar e propor novos discursos transformadores.

Na dimensão genética da consciência histórica, surge, de maneira decisiva, o aspecto da passagem do tempo na vida humana. Nessa dimensão, Luis Fernando Cerri (2011, p.102) indaga que o passado é apresentado na forma de uma sequencia processual na qual às mudanças são decisivas para a compreensão da realidade. Os alunos que mobilizaram essa dimensão da consciência histórica avançaram na noção de História, isto porque, conseguiram se perceber enquanto sujeitos históricos, apropriando-se do conhecimento histórico e entendendo que são as ações humanas que explicam e movem as mudanças e permanências no tempo, no espaço e na História.

Nesse sentido, algumas expressões podem ser destacadas: 
Expressões da dimensão genética da consciência histórica

PM4 L1: Quem faz a história somos nós, seres humanos.

PM17 L1: (...) tudo o que vivemos hoje faz parte da história.

PM13 L1: (...) a história é feita da nossa vivência.

GM10 L1-2: (...) porque assim consigo entender melhor a sociedade de hoje.

GM22 L1-3: (...) porque você fica conhecendo o que aconteceu no passado que explica muita coisa que está acontecendo no presente.

GM15 L1-4: (...) na história você aprende não só sobre a história, mas de onde viemos, nossos antepassados, cultura, valores, democracia, história do país dos estados, política, uma abertura para uma visão mais diferente de ver a vida e aprender mais.

GM 14 L1-3: (...) história faz parte da nossa vida por isso nós precisamos saber como era a história no passado para compreender o presente e buscar orientação para o futuro.

GM10 L1-3: (...) porque a história é uma construção, não podemos estudar sem a ligação das três épocas, presente, passado e futuro.

Nessa perspectiva, infere-se que a vida é orientada pela mudança e pelo conhecimento em suas próprias relações em direção ao futuro, e também, conforme Luis Fernando Cerri (2011, p.103), pela possibilidade de exceder as oportunidades que haviam no passado. Convém ressaltar os dados relativos à primeira questão no qual os alunos enfatizaram que a História é principalmente uma forma de "entender a vida pessoal como parte das mudanças que ocorrem na História" e "mostra o que está por trás da maneira de viver no presente e explica os problemas atuais".

Entre essas constatações e aproximações é possível inferir que o ensino e a aprendizagem da História têm desempenhado um papel fundamental para os alunos, no que se refere à formação da consciência histórica. Os resultados apontam que o conhecimento histórico não vem sendo tomado pelos alunos como algo sem sentido ou como simples acúmulo de conteúdo escolar. Ao contrário disso, o conhecimento histórico possui significado e tem proporcionado novas formas de orientações, interpretações, leituras e visões de mundo.

\section{Considerações finais}

Ao longo desse artigo procurou-se abordar uma concepção de consciência histórica e ensino de História, que, uma vez articuladas, podem fornecer referenciais e possibilidades de orientação dos seres humanos no tempo, no espaço, na sociedade em que vivem. 
Almejou-se também, por meio dessas concepções, sugerir uma alternativa para o enfrentamento das dificuldades que existem no campo do ensino e aprendizagem em História a partir do entendimento das ideias e conceitos dos alunos sobre a História e sua função social.

Segundo Flávia Caimi (2009, p.79), é importante valorizar os conhecimentos prévios dos alunos, bem como a maneira pelo qual mobilizam esses conhecimentos. Por meio dessas ideias, aliadas ao ensino enquanto processo construtivo, os alunos podem apropriar-se do conhecimento e desenvolver novas formas de pensar historicamente e atribuir sentido a suas experiências no tempo e no contexto social em que vivem.

Seguindo tais princípios, a pesquisa aqui relatada sustentou a necessidade de, no processo de ensino, levar em conta a subjetividade dos alunos, suas experiências sociais com a disciplina de História. O conhecimento histórico é um mecanismo essencial para que o aluno possa se apropriar de um olhar consciente para sua própria sociedade e para si mesmo. A História, juntamente com outras áreas do conhecimento, pode potencializar o desenvolvimento da formação humana, possibilitar novas formas de inserções e adaptações na vida cotidiana e, sobretudo, contribuir para o exercício da cidadania.

Ao pontuar a análise final desse texto observou-se que para os alunos jovens e adultos participantes da pesquisa, diferente da opinião de senso comum que prevê que os alunos da EJA não possuem interesse na História, tampouco possuem conhecimentos sobre o assunto, a História é uma disciplina escolar que deve ser valorizada, pois potencializa a compreensão do mundo e suas constantes transformações, enquanto contribui para a orientação das ações humanas no tempo, no espaço, na sociedade.

No contexto das questões ora discutidas, considera-se que somente um ensino de História pautado no diálogo entre professores e alunos, que valorize as muitas experiências, as histórias, as memórias, as vivências, a ideias, os saberes e as opiniões, é que poderá contribuir para a formação e o desenvolvimento da consciência histórica.

Nesse sentido, enfatiza-se a necessidade de se buscar nas características dos alunos os elementos necessários para elencar debates e reflexões acerca de questões históricas que busquem superar a simples reprodução de conteúdos. Com isso, professores e alunos podem construir no espaço escolar um local que possibilite o entendimento da realidade, e também, de acordo com Luis Fernando Cerri (2011, p.126), da compreensão da diferença, da alteridade, tanto para ensinar a convivência nas sociedades quanto para ensinar a julgar o próprio sistema político e social vivido.

Em suma, o aprofundamento no tipo de pesquisa aqui relatada possui um grande potencial, uma vez que produz informações privilegiadas, e muitas vezes essenciais, para o aprimoramento das questões relativas ao ensino e aprendizagem da História na EJA. 
Assim, desenvolver um trabalho com base em ideias, conceitos e saberes históricos de alunos, remete à compreensão de que uma das funções do ensino de História consiste justamente na possibilidade de alunos e professores intervirem na realidade em que vivem, a partir de diálogos estabelecidos entre o presente e o passado.

Finaliza-se, pois, advogando a necessidade de se compreender a sala de aula do ensino Médio da EJA como um espaço propício para o compartilhamento de conhecimentos, ou nas palavras de Maria Auxiliadora Schmidt (2002, p.57) como um espaço onde "uma relação de interlocutores constroem sentidos".

\section{Referências}

BARCA, Isabel. Marcos de consciência histórica de jovens portugueses. Currículo sem fronteiras, v. 7, n. 1, p. 115-126, jan./jun., 2007.

BARDIN, Laurence. Análise de Conteúdo. Lisboa: Edições 70, 1977.

BERGMANN, Klaus. A História na Reflexão Didática. Revista Brasileira de História. São Paulo, v. 9, n. 19, p. 29-42, set/fev1990.

CAIMI, Flávia Eloisa. História escolar e memória coletiva: como se ensina? Como se aprende. In: ROCHA, Helenice Aparecida Bastos; MAGALHAES, Marcelo de Souza; GONTIJO, Rebeca. (orgs.) A escrita da história escolar: memória e historiografia. Rio de Janeiro: FGV, 2009.

CARDOSO, Oldimar Pontes. A Didática da História e o Slogan da formação de cidadãos. (Tese de doutorado em Educação),USP, São Paulo, 2007.

CERRI, Luis Fernando. Ensino de História e Consciência histórica. Rio de Janeiro: Editora FGV, 2011.

Os conceitos de consciência histórica e os desafios da didática da história. Revista História Regional, Curitiba, v. 6, p. 93-112, 2001.

.Para uma definição de didática da história. Revista Brasileira de História. São Paulo, v. 28, n. 55, p. 153-170, jun.2008.

; MOLLAR, Jonathan. Jovens diante da história: o nacional e o internacional na América Latina. Práxis Educativa, Ponta Grossa, v.5, n.2, p. 161-171. 
COSTA, José Raimundo Lisboa da. Ensino de História na Educação de Adultos: entre o ensinado e o vivido - as dimensões da consciência histórica. (Tese de Doutorado em Educação), UFMG, Belo Horizonte, 2005.

ECKER Alois. Didactica de la historia orientada a los processos. Nuevos caminhos em la formacion de maestros (as) de educacion superior en la Universidad de Viena, 2002. Disponível em: <hppt://www.univie.ac.at/wirtschaftsgeschichte/pdf_gdes.html $>$ Acesso em: dez. de 2012.

FONSECA, Selva Guimarães. Didática e Prática de ensino de história: Experiências, reflexões e aprendizados. São Paulo: Papirus, 2003.

GERMINARI, Geyso Dongley. A história da cidade, consciência histórica e identidades de jovens escolarizados. (Tese de Doutorado em Educação),UFPR, Curitiba, 2010.

HICKENBICKI, Cláudia. Lembrança, interesse e história substantiva: significados do ensino e aprendizagem da história para os sujeitos da educação de jovens e adultos. (Dissertação de mestrado em Educação), UFPR, Curitiba, 2009.

IPARDES. Instituto Paranaense de Desenvolvimento Econômico e Social. Caderno Estatístico do Município de Guarapuava. Dezembro de 2012.

JOHNSON, A. G. Dicionário de sociologia. Rio de Janeiro: Zahar, 1997.

KUSNICK, Marcos. Filosofia cotidiana da História: uma contribuição para a Didática da História. (Dissertação de mestrado em Educação), UEPG, Ponta Grossa, 2007.

MORAES, Roque. Uma tempestade de luz: a compreensão possibilitada pela análise textual discursiva. Ciência \& Educação, v. 9, n. 2, p. 191-21, 2003.

MURINELLI, Glaucia Ruivo. Narrativas de futuros professores de história sobre os afrobrasileiros no contexto do pós-abolição: um estudo em meio a lei federal 10.639/03. (Mestrado em História) UEL, Londrina, 2012.

PACIEVITCH, Caroline. Consciência Histórica e Identidade de Professores de História. (Dissertação de mestrado em Educação), UEPG, Ponta Grossa 2006.

PÁDUA, Josiane Soares. O processo de construção do conhecimento histórico para alunos em educação de jovens e adultos: um olhar para as práticas de leitura e escrita. (Dissertação de Mestrado em Educação), UNESP, Rio Claro 2008.

RÜSEN, Jörn. Aprendizagem histórica: fundamentos e paradigmas. Curitiba: W.A. Editores, 2012. 
. Razão histórica. Teoria da história: os fundamentos da ciência histórica. Brasília: Editora da UnB, 2001.

_._. _. Cartografias Temporais: metodologias da pesquisa em consciência histórica. Educação e Realidade, Porto Alegre, v. 36, n.1, p. 59-81, jan./abr 2011b.

. Didática da História: passado, presente e perspectivas a partir do caso alemão. In: Praxis Educativa. Ponta Grossa, v.1, n.2, p.07-17, jul/dez 2006.

_._. . História Viva: formas e funções do conhecimento histórico. Brasília: Editora da UnB, 2007.

. O desenvolvimento da competência narrativa na aprendizagem histórica: uma hipótese ontogenética relativa a consciência moral. In: SCHMIDT, Maria; BARCA, Isabel; MARTINS, Estevão (Org.). Jörn Rüsen e o Ensino de História. Curitiba: Editora UFPR, 2010, p. 51-77.

SCHMIDT, Maria Auxiliadora. A formação do professor de história e o cotidiano na sala de aula. In: BITTENCOURT, Circe. O saber histórico na sala de aula. São Paulo: Editora Contexto, 2002. 


\section{ANEXO 1}

Na questão 15 você encontrará uma pequena história que implica em uma tomada de decisão final. Existem quatro alternativas, por isso leia atentamente e marque somente uma delas.

15. Imagine que você tem uma afilhada cujo nome é Camila de $\mathbf{1 5}$ anos. Os pais de Camila sempre confiaram a você os preceitos, valores e tradições da família, e por isso, sua escolha em batizá-la. Em certo dia, Camila bate a sua porta angustiada e desesperada dizendo que seus pais querem que se case com o filho de um agricultor rico da cidade vizinha que ela sequer conhece, nem mesmo tem vontade de casar ainda. Camila pede para que você impeça o casamento, uma vez que você é o padrinho/madrinha. Neste caso, o que você faria?

( ) Você reconhece os compromissos para com a família de Camila e argumenta com a jovem que seus pais e avós casaram-se muito cedo, sempre a gosto da família, e constituíram famílias sólidas, bem estruturadas e felizes. Camila deveria seguir este exemplo, pois isso seria o mais correto a se fazer.

( ) Devido aos seus compromissos de Padrinho/Madrinha, você se sente na obrigação de manter Camila dentro das tradições da família. Deste modo, você aconselha a jovem que obedeça aos seus pais, uma vez que as normas e regras sempre são assim há 3 gerações e não é correto desrespeitar tais costumes.

( ) Você reconhece que possui um vínculo de compromisso com Camila e sua família, porém nota que visivelmente a jovem não está preparada para se casar, tão pouco com alguém que jamais viu antes. Em outras épocas, contextos e situações os casamentos arranjados são compreensíveis, mas não válidos para Camila. Neste caso, você se propõe a ir conversar com a família dela, buscando compreender as razões que levaram a exigência do casamento, e, além disso, também sugere a Camila que não fuja, mas tente conversar com seus pais, garantindo que prestará sua ajuda no que for possível.

( ) Você diz a Camila que não acredita mais que os compromissos de Padrinho/Madrinha possam autorizar a interferência em decisões familiares. Por outro lado você também argumenta que hoje os tempos são outros, os casamentos arranjados são coisas do passado e não possuem validade alguma. Neste caso, você diz a Camila que ela pode negar a se casar e a orienta a buscar apoio a sua decisão. 